\title{
Research on the Signal Control Design of Right-turn Vehicle in Urban Traffic
}

\author{
Sun Mengyi \\ MOE Key Laboratory for Urban Transportation Complex Systems Theory and Technology \\ Beijing Jiaotong University \\ Beijing, China \\ 12120906@bjtu.edu.cn
}

\begin{abstract}
Mixed traffic, especially the conflict between motorized and non-motorized vehicles, is a distinctive feature of urban traffic in China. Oriented on the signalized intersections with right-turn vehicles excluded from signal control in Tianjin Municipality, the study researches on the laws of the arrival and release of bicycles at signalized intersections based on the traffic characteristics of bicycles. Then the study delves into the characteristics of conflicts between motorized and non-motorized vehicles featuring mixed traffic at intersections. Given these analyses, the study proposes the method of signal control and the corresponding parameters of right-turn motorized vehicles, and evaluates the effectiveness of this method for easing the conflict between right-turn motorized vehicles and straight going bicycles.
\end{abstract}

Index Terms-Mixed traffic, Signalized intersection, Conflict between right-turn vehicles and bicycles, Signal control scheme.

\section{INTRODUCTION}

China is known as the "bicycle kingdom", and bicycle accounts for $35 \%-80 \%$ of the passenger capacity. The number of bicycles is growing at $8 \%$ annually. The interference between bicycles and motorized vehicles has been a more and more serious problem in terms of the limited development of road space. In order to reduce the interferences and conflicts of mixed traffic flows crossing through the intersection, reasonable organization, management and control of signalized intersections can be mutually used for non-mixed traffic flow to ensure the safe passing.

\section{THE ANALYSIS ON THE EFFECT OF RIGHT-TURNING VEHICLES AND STRAIGHT GOING BICYCLES AT SIGNAL INTERSECTIONS}

Signalized intersections without right-turn control are mostly universal in Chinese urban traffic. Right-turning vehicles randomly arrive at the intersection and cross through the intersection at any time, while straight-going bicycles can only cross through the intersection with straight-going motor vehicles when the straight green traffic lights become green. Based on researches at signalized Intersections a fact has been found that non-motorized vehicles have obvious features when crossing through the intersections, especially during peak hours. ${ }^{[1]}$ The study has divided traffic flow into two stages in order to make further analyses: in the first stage, the first stream of traffic flow as a group enter the intersection when traffic light becomes green, which includes those bicycles stopping at the stop line during the red light and those when the light lighted, What is more, the first stream of traffic flow accounted for a large proportion of whole bicycle traffic flow crossing through the intersection during the entire green light, though the time is very short. In terms of the second stage, the bicycle flow randomly crosses through the intersection, including other bicycles entering the intersection during the same green light. Straight-going bicycle flow in the two stages will be subject to the effect of the right-turning vehicles.

The study researches on no-entering of right-turn motors in the early hours of straight-going green light, so that the first stream of traffic flow can pass the intersection smoothly. The intersection of Fukang Road and Baidi Road in Tianjin is selected as the object of research. The observed traffic flow of right-turning vehicles and straight going bicycles crossing through the east entrance lane of this intersection is large. There are many traffic sources of attraction such as Nankai University kindergarten, Fukangli residential quarter, CR Vanguard. During evening peak hours the conflict is more obvious. The following data have been collected for east entrance lane of this intersection.

\section{A. Based data survey of traffic flow}

Data collection include: the basic data of the selected entrance lane of the intersection such as base conditions and the existing signal timing, and the time of right-turning vehicles and straight going bicycles traveling through the intersection during the common and evening peak.

The intersection of Fukang Road and Baidi Road in Tianjin is selected as the object of research. The south entrance lane of this intersection is narrow and traffic flow is small so that it can be seen as a T-intersection. The based data of transportation infrastructure of this intersection are shown as follows in Table I and Table II.

TABLE I. BASED DATA OF FuKANG EAST ENTRANCE LANE

\begin{tabular}{|c|c|c|c|c|c|c|}
\hline Lane & \multicolumn{5}{|c|}{ Motorized vehicle } & $\begin{array}{c}\text { Bicy } \\
\text { cle }\end{array}$ \\
\hline $\begin{array}{c}\text { Lane } \\
\text { Widt }\end{array}$ & $\begin{array}{c}\text { Exclusive } \\
\text { left-turn }\end{array}$ & $\begin{array}{c}\text { Exclusive } \\
\text { straight } \\
\text { lane }\end{array}$ & $\begin{array}{c}\text { Exclusive } \\
\text { straight } \\
\text { lane } 3.75 \mathrm{~m}\end{array}$ & $\begin{array}{c}\text { Exclusive } \\
\text { lane }\end{array}$ & $\begin{array}{c}\text { Exclusive } \\
\text { lane } \\
\text { right-turn } \\
\text { lane }\end{array}$ & $5 \mathrm{~m}$ \\
& $3.75 \mathrm{~m}$ & $3.75 \mathrm{~m}$ & $3.75 \mathrm{~m}$ & $3.75 \mathrm{~m}$ & \\
\hline
\end{tabular}


This study aims at easing the conflict between right-turning vehicles and straight-going bicycles. We only need the based data of east entrance lane of Fukang Road to make a new signal timing design for right-turning vehicles.

TABLE II. The Signal Timing Data of Fukang East Entrance Lane

\begin{tabular}{|c|c|c|c|c|}
\hline $\begin{array}{c}\text { Light } \\
\text { Color }\end{array}$ & $\begin{array}{c}\text { Green } \\
\text { Light }\end{array}$ & $\begin{array}{c}\text { Yellow } \\
\text { Light }\end{array}$ & Red Light & $\begin{array}{c}\text { Cycle } \\
\text { Time }\end{array}$ \\
\hline Duration & $110 \mathrm{~s}$ & $3 \mathrm{~s}$ & $95 \mathrm{~s}$ & $208 \mathrm{~s}$ \\
\hline
\end{tabular}

The Interference between motorized vehicles and bicycles is caused by mutual crossing through the intersection ${ }^{[2]}$. Due to the Interference, this study analyses the impact of speed of straight going bicycle and right-turning vehicles using collected relevant data. Speed survey is the important item of a road traffic flow organization, including the survey of spot speed and interval speed. The methods of speed survey in this article are shown as follows:

1) Artificially measure the straight-going distance of straight-going bicycles and the right-turning distance of rightturning vehicles. The distance is from the stop line when vehicles firstly enter the intersection to the stop line leaving the intersection.

2) Select the appropriate samples; record the time of vehicles by stopwatches when crossing through the intersection in terms of conflict and non-conflict state. In order to avoid bias, this study adopted a random sampling method.

The data collected by the above research methods during the high, flat peak are shown in Table III and Table IV.

TABLE III. Time Data of The Vehicles Crossing The Intersection at HIGH PEAK

\begin{tabular}{|c|c|c|c|c|c|c|}
\hline Category & \multicolumn{3}{|c|}{$\begin{array}{l}\text { Right-turning motor } \\
\text { vehicles with conflict }\end{array}$} & \multicolumn{3}{|c|}{$\begin{array}{c}\text { Right-turning motor } \\
\text { vehicles without conflict }\end{array}$} \\
\hline \multirow{3}{*}{$\begin{array}{l}\text { Time of } \\
\text { crossing the } \\
\text { intersection } \\
(\mathrm{s})\end{array}$} & 27.91 & 15.58 & 9.86 & 11.35 & 7.10 & 8.74 \\
\hline & 11.16 & 18.07 & 22.92 & 10.04 & 8.37 & 8.43 \\
\hline & 11.93 & 31.21 & 13.96 & 8.97 & 13.83 & 13.12 \\
\hline $\begin{array}{l}\text { Average } \\
\text { time }(\mathrm{s})\end{array}$ & \multicolumn{3}{|c|}{18.06} & \multicolumn{3}{|c|}{9.28} \\
\hline $\begin{array}{l}\text { Speed } \\
(\mathrm{m} / \mathrm{s})\end{array}$ & \multicolumn{3}{|c|}{1.16} & \multicolumn{3}{|c|}{2.26} \\
\hline Category & \multicolumn{3}{|c|}{$\begin{array}{c}\text { Straight going bicycles with } \\
\text { conflict }\end{array}$} & \multicolumn{3}{|c|}{$\begin{array}{c}\text { Straight going bicycles } \\
\text { without conflict }\end{array}$} \\
\hline \multirow{3}{*}{$\begin{array}{l}\text { Time of } \\
\text { crossing the } \\
\text { intersection } \\
(\mathrm{s})\end{array}$} & 17.38 & 14.97 & 9.83 & 9.14 & 9.69 & 12.02 \\
\hline & 13.89 & 13.91 & 18.30 & 13.79 & 9.48 & 11.62 \\
\hline & 13.12 & 12.75 & 13.26 & 11.12 & 8.71 & 8.60 \\
\hline $\begin{array}{l}\text { Average } \\
\text { time }(\mathrm{s})\end{array}$ & \multicolumn{3}{|c|}{14.17} & \multicolumn{3}{|c|}{10.69} \\
\hline $\begin{array}{l}\text { Speed } \\
(\mathrm{m} / \mathrm{s})\end{array}$ & \multicolumn{3}{|c|}{2.68} & \multicolumn{3}{|c|}{3.55} \\
\hline
\end{tabular}




$$
g_{e R}=g_{R}-L
$$

Where $S_{R}$ - the saturation flow of exclusive right-turn lane, $\mathrm{g}_{\mathrm{eR}}$ - the effective green time of right-turn phase, $\mathrm{C}$ - signal cycle length, $\mathrm{C}=208 \mathrm{~s}$,

$\mathrm{g}_{\mathrm{R}}$ - the display green time of right-turn phase, this intersection does not control right-turn, so $g_{R}=208$ s.

$\mathrm{L}$ - the loss time of right-turn phase, $\mathrm{L}=3 \mathrm{~s}$.

The progress of calculating the saturation flow of exclusive right-turn lane is shown as follows:

$$
\begin{gathered}
S_{R}^{\prime}=3600 / 26 \times 4=554 \mathrm{pcu} / \mathrm{h} \\
C A P_{R}=S_{R}^{\prime} \times g_{\text {eR }} / \mathrm{C}=554 \times(208-3) / 208=546 \mathrm{pcu} / \mathrm{h}
\end{gathered}
$$

\section{THE RESEARCH OF IMPROVEMENT PLAN FOR THE CONFLICT BETWEEN MOTORIZED AND NON-MOTORIZED VEHICLES AT THE INTERSECTION}

\section{A. Traffic organization method}

Intersection release method refers to the release of the motorized vehicles, non-motorized vehicles and pedestrians at the intersections. The release of non-motorized vehicles general separates to spatial separation, temporal separation and spatial separation. As to select which kind of the release, the key is to observe the size of the traffic flow of the bicycle crossing through the intersection ${ }^{[4]}$. Once the method has been selected, the right of ways for the tread on the markings and the signals must be confirmed, the target is to make the different types of traffic flow follow the rule of "see the light go", which means crossing through the intersection according to their flow direction and the green light ${ }^{[4]}$.

\section{B. The channelization of Intersection}

The intersection traffic organization focused on separating conflicts, if necessary, the drainage ways can be used to control the location and nature of the conflict point, and channelization should pay attention to the following aspects of the problem ${ }^{[5]}$.

1) The entrance lane of bicycle should be narrow, while exit lane should be wide in order to increase the attractiveness of the bicycle flow.

2) The point of conflicts are relatively fixed and centralized by using available space in the area of the intersection as far as possible.

3) Separations between motorized and non-motorized vehicles at the entrance lane should be set, reducing the running resistance of the motorized vehicles.

4) The exit lane of the intersection should be areas designated as a continuous lane, reducing the distance between vehicles traveling through the intersection after the lane is changed.
5) Setting the prohibitive driving area or designate driving area of non-motorized vehicles combined with the intersection release method.

\section{The design of signal control}

The time of right-turn red lights has relationships not only with the amount of traffic flow at the first stage, but with the width of the bicycle lanes and road surface conditions, this paper focuses on the relationship between traffic density of straight going bicycle and the time of the right-turn red light. The average queue length of bicycles is $20 \mathrm{~m}$ during the observation period, the width of bicycle lane is $5 \mathrm{~m}$, queuing green bicycles cover an area of $100 \mathrm{~m}^{2}$.Data are sorted out as follows in Table V (peak hours).

TABLE V. BICYCLE TIME-DENSITY ON FUKANG ROAD AND BAITI ROAD

\begin{tabular}{|c|c|c|c|c|}
\hline $\begin{array}{c}\text { The Time of } \\
\text { The First } \\
\text { Stage(s) }\end{array}$ & 16.96 & 26.28 & 27.55 & 36.60 \\
\cline { 2 - 5 } & 25.65 & 25.82 & 21.47 & 25.95 \\
\hline $\begin{array}{c}\text { The First Stage } \\
\text { Number of } \\
\text { Bicycles }\end{array}$ & 19 & 44 & 56 & 60 \\
\cline { 2 - 5 } & 42 & 46 & 58 & 73 \\
\hline $\begin{array}{c}\text { Bicycle } \\
\text { Density(vehicle/ } \\
\mathrm{m}^{2} \text { ) }\end{array}$ & 0.19 & 0.44 & 0.56 & 0.60 \\
\cline { 2 - 5 } & 0.42 & 0.46 & 0.58 & 0.73 \\
\hline
\end{tabular}

Then the relationship between bicycle density and time of the first stage is shown in Fig.2.

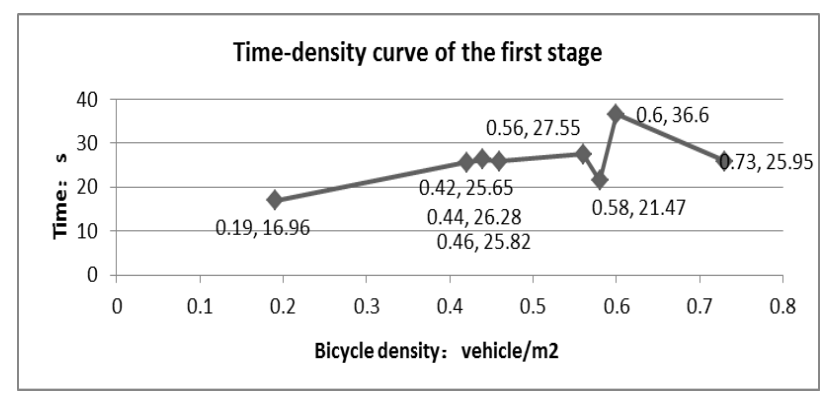

Fig. 2. The relationship between the bicycle density and time of the first stage.

By analyzing the chart, right-turn red light is set as $27 \mathrm{~s}$, with straight going green light lighting at the same time, the remaining cycle time are displayed in green.

\section{EVALUATION OF CONTROL EFFECT}

The control effect of right-turning vehicles cannot show timely, this paper adopted the data of flat peak as the effect reference of the control, and the results are shown in Table VI.

TABLE VI. The Time of Right-TURning VeHICles CRossing The INTERSECTION AT FLAT PEAK

\begin{tabular}{|c|c|c|c|c|c|}
\hline \multirow{3}{*}{ Time(s) } & 5.26 & 5.17 & 4.82 & 5.13 & 3.96 \\
\cline { 2 - 6 } & 5.41 & 3.65 & 3.85 & 4.18 & 4.33 \\
\cline { 2 - 6 } & 4.50 & 3.82 & 5.26 & 5.12 & 3.34 \\
\cline { 2 - 6 } & 5.25 & 3.38 & 4.65 & 4.41 & 4.63 \\
\hline $\begin{array}{c}\text { Average } \\
\text { time } \\
(\mathrm{s})\end{array}$ & 4.462 & \\
\hline
\end{tabular}


Then

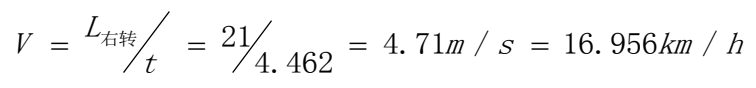

The capacity of right-turn lane:

$$
C=3600 / h_{t} \times \lambda, \lambda=(208-27) / 208=0.87
$$

Headway:

$$
h_{t}=L / V
$$

$\mathrm{L}=$ safe braking distance SSD + safe distance:

$$
S S D=2.5 V+V^{2} / 254(\phi+i)
$$

Safe distance is to ensure that the car safely came to a stop in front of the obstacle, from the actually observations safe distance is taken as the distance during waiting time of the vehicles of $1.5 \mathrm{~m}$; safe braking distance include the braking distance and driving distance during the driver's reaction time, the reaction time is generally $1.5-2 \mathrm{~s}$, generally the time of driver reacting to action is $1.5 \mathrm{~s}$, and the effect time of braking is $1 \mathrm{~s}$, so the total reaction time is $2.5 \mathrm{~s}$ which i-road longitudinal slope, $i=0 ; \varnothing$ - the coefficient of adhesion between tire and road; $\emptyset=0.7-1.0$ in terms of drying cement pavement, here $\emptyset=1$.Then

$$
\begin{gathered}
S S D=2.5 \times 4.71+16.956^{2} / 254(1+0)=12.9 m \\
h_{t}=(12.9+1.5) / 4.71=3.06 \mathrm{~s} / \text { vehicle } \\
C=3600 / 3.06 \times 0.87=1024 \text { vehicle } / h
\end{gathered}
$$

\section{CONCLUSIONS}

This article makes survey and data processing on the intersection of Fukang Road and Baidi Road. Firstly, the study makes analysis on the impact caused by the conflict between straight going bicycles and right-turning vehicles, including the impact of speed and traffic capacity. According to the research of the conflict, taking the existing intersection channelization and conflict types into account, this study turns the original control mode into the mode of controlling right-turning vehicles, separating the straight going bicycles during the straight green light into two stages; the first stage is of vital importance. Based on the analysis of data, the actual capacity of right-turning vehicles is $546 \mathrm{pcu} / \mathrm{h}$, which improves to $1024 \mathrm{pcu} / \mathrm{h}$ after improvement. The red light has been set to controlling the straight going bicycles at the first stage, reducing the delay time caused by the conflict between the two and increasing the capacity of vehicles crossing the intersection to the maximum. It turns out that the improvement method proposed has positive effects on increasing the capacity of right-turning vehicles and provides reference comments for the traffic managers.

\section{REFERENCES}

[1] Brilon W. Koeniga R. Troutbeck R J. "Useful estimation procedures for critical gaps," Transportation Research Part A, vol.33, pp: 161-186, April 1999.

[2] Huang Di, Qian Dalin, and Zhao Chunlong, "Study on Behavior of Right-Turning Motor Crossing Through Bicycles at Grade Intersection," in Journal of Beijing Jiaotong University, China, vol.30, pp:23-26, June 2006.

[3] Wu Bing, and Li Ye, "Traffic Management and Control," Beijing: China Communications Press, 2009. (in Chinese)

[4] Zhai Zhongmin, and Ren Futian, "Road Traffic Organization Optimization," Beijing: China Communications Press, 2004. (in Chinese)

[5] Guo Yanming, Yu Quan, Liu Jinguang, Liu Peihua, Zhang Hui, and Rong Jian, "Study on bicycle leading phase in the shared right-turn signalized intersection," in ITS CC, China, pp: 178185, May 2008. 